\title{
Chemical Constituents from Artemisia annua and Vitex agnus-castus as New Aromatase Inhibitors: In-vitro and In-silico Studies
}

\author{
Hend M. Dawood*, Eman Shawky, Hala M. Hammoda, Aly M. Metwally, Reham S. Ibrahim \\ Department of Pharmacognosy, Faculty of Pharmacy, Alexandria University, Egypt.
}

*Corresponding author: Hend M. Dawood, email: henddawoodpharm@hotmail.com

Received June 13 $3^{\text {th }}, 2020$; Accepted September $24^{\text {th }}, 2020$.

\section{DOI: http://dx.doi.org/10.29356/jmcs.v64i4.1236}

\begin{abstract}
Aromatase inhibitors are important in certain cancers such as breast cancer in postmenopausal women. In this study, eight constituents from Artemisia annua L. and Vitex agnus-castus L. were isolated and evaluated for their aromatase inhibitory activity using in-vitro fluorimetric assay. All tested compounds possessed moderate to strong inhibitory activity with $\beta$-sitosterol and myricetin-3,7,4'-trimethyl ether being the most active with $\mathrm{IC}_{50}$ values of 0.13 and $0.25 \mu \mathrm{M}$, respectively. Compounds were subjected to induced fit docking (IFD) where $\beta$-sitosterol, possessed comparable interaction patterns to the natural co-crystallized ligand androstenedione. Furthermore, Absorption, Distribution, Metabolism, Excretion and Toxicity (ADME\&T) properties of the compounds were evaluated revealing that all compounds' properties - except some of $\beta$ sitosterol related to solubility - lied within the acceptable range for human use, thereby considered as competent drug-like molecules. These findings could qualify $\beta$ - sitosterol, myricetin-3,7,4'-trimethyl ether and domesticoside as lead compounds for the development of new aromatase inhibitors.
\end{abstract}

Keywords: Aromatase inhibitors; Artemisia annua L. and Vitex agnus-castus L.; $\beta$-sitosterol; myricetin-3,7,4'trimethyl ether; domesticoside.

Resumen. Los inhibidores de la aromatasa son importantes en ciertos tipos de cáncer, como el de seno en mujeres posmenopáusicas. En este estudio, se aislaron y evaluaron ocho compuestos extraídos de Artemisia annua L. y Vitex agnus-castus L. para determinar su actividad inhibidora de la aromatasa mediante un ensayo fluorimétrico in vitro. Todos los compuestos ensayados poseían una actividad inhibidora de moderada a fuerte, siendoel $\beta$-sitosterol y la miricetina-3,7,4'-trimetiléter los más activos con valores de CI50 de 0.13 y $0.25 \mu \mathrm{M}$, respectivamente. Los compuestos se sometieron a acoplamiento de ajuste inducido (IFD) en el que el $\beta$ sitosterol poseía patrones de interacción comparables a los del ligando cocristalizado natural androstenediona. Además, se evaluaron las propiedades de absorción, distribución, metabolismo, excreción y toxicidad (ADME $\& \mathrm{~T}$ ) de los compuestos, lo que reveló que las propiedades de todos los compuestos, excepto algunas de $\beta$ sitosterol relacionadas con la solubilidad, se encontraban dentro del rango aceptable para uso humano, por lo que se les puede considerar como moléculas competentes similares a fármacos. Estos hallazgos podrían calificar al $\beta$-sitosterol, miricetin-3,7,4'-trimetil éter y al domesticoside como compuestos principales para el desarrollo de nuevos inhibidores de la aromatasa.

Palabras clave: Inhibidores de aromatasa; Artemisia annua; Vitex agnus-castus; $\beta$-sitosterol; miricetin-3,7,4'trimetiléter; domesticosido. 


\section{Introduction}

Aromatase is a cytochrome P450 enzyme that is responsible for the conversion of androgens into estrogens.[1] The level of estrogens has been observed to be as much as twenty-fold higher in breast cancer tissues than in the circulating plasma, suggesting the possibility of breast tumor due to over expression of aromatase enzyme in such tissues. Consequently, inhibition of this enzyme has significant effect on suppressing hormonal dependent breast cancers.[2] Natural products from foods or traditional medicine were reputed for treating many gynaecological ailments due to their possible aromatase inhibitory activity.[3] Artemisia annua L. (also known as sweet wormwood or quinghao), was used traditionally in treating impotence [4] while Vitex agnus- castus L. (also known as Chaste tree or Abraham's balm) was used as an emmenagogue, aphrodisiac, and regulates hormones.[5]

Discovery of novel drugs or lead compounds is aided by computational techniques, among which, docking studies provided information about the interaction between ligand and the protein binding site.[6] There are two types of docking; rigid and induced fit docking (IFD). In rigid docking, the ligand is treated as flexible while the receptor is kept rigid during docking, however; IFD allows for flexiblilty of ligand and minor adjustments to flexible side chains in the protein active site that are crucial for ligand accommodation affording accurate molecular interactions between ligand and the protein.[7] A great concern should be also paid to the pharmacokinetic (Absorption, Distribution, Metabolism, Excretion and toxicity: ADME\&T) profiles - for evaluating the drug-likeness of compounds before synthesis.[8]

Based on our previous work that aimed to search for new plants as promising natural aromatase inhibitors, two plants; A. annua and V. agnus-castus exhibited the highest in-vitro inhibitory activities when compared to other tested plant extracts.[9] This drove our interest to mine for the active ingredients responsible for such promising activity. In this search, isolation of compounds from these plant extracts was performed followed by testing their aromatase inhibitory activity using fluorescence-based in-vitro assay. IFD was also conducted aiming to provide an explanation for the traditional uses of both plants [10] followed by drug-likeness studies on the identified compounds.

\section{Experimental}

\section{Isolation of active constituents from plant material}

Two plants named; A. annua L. (Voucher sample number AR001, Figures S1a and $\mathrm{S} 1 \mathrm{~b}$ ) and $V$. agnuscastus L (Voucher sample number AR005, Figures S1c and S1d) were used in this study. Aerial parts of $A$. annиa were collected from a cultivated area in Cairo, while V. agnus-castus fruits were collected from Giza zoo. Plant materials were identified by Mrs. Teresa Labib, Taxonomist at the El-Orman Botanical Garden, Giza. To complement the authentication of plants, samples were also compared with the Kew garden's (https://www.kew.org) reference samples revealing matched descriptions. A voucher sample of each plant was kept at the Pharmacognosy Department, Faculty of pharmacy, Alexandria University.

Dried aerial parts of A. аппиа $(3.5 \mathrm{~kg})$ were extracted with $70 \%$ ethanol, filtered and concentrated to obtain an $850 \mathrm{~g}$ residue. The hydroalcoholic extract (ethanol: water, 1:1 $\mathrm{v} / \mathrm{v}$ ) was partitioned with organic solvents of increasing polarities (starting with light petroleum then methylene chloride $\left(\mathrm{CH}_{2} \mathrm{Cl}_{2}\right)$ followed by ethyl acetate and finally $n$-butanol) yielding $400,62.8,136.7$ and $48 \mathrm{~g}$, respectively. Twenty grams from the methylene chloride fraction was repeatedly chromatographed using normal silica gel columns $\left(\mathrm{CH}_{2} \mathrm{Cl}_{2} 100 \%\right.$, then gradual increase in the polarity by addition of methanol (MeOH) to $100 \%$ ) to yield subfractions 21 (eluted from $0.5 \% \mathrm{MeOH}$ in $\mathrm{CH}_{2} \mathrm{Cl}_{2}$ ), 24 (eluted from $1 \% \mathrm{MeOH}$ in $\mathrm{CH}_{2} \mathrm{Cl}_{2}$ ) and 40 (eluted from $20 \% \mathrm{MeOH}$ in $\mathrm{CH}_{2} \mathrm{Cl}_{2}$ ). Compound (1) was generated from subfraction 21 by crystallization and further purification on Sephadex LH20 column chromatography. Chromatographic purification of subfraction 24 (using light petroleum and $\mathrm{CH}_{2} \mathrm{Cl}_{2}$ ) followed by crystallization and purification on Sephadex $\mathrm{LH} 20$ yielded compounds (2) and (3), respectively. Compound (4) was obtained from subsequent normal phase chromatographic separation of subfraction 40 using $\mathrm{MeOH}$ and $\mathrm{CH}_{2} \mathrm{Cl}_{2}$ then crystallization. Similarly, fresh $V$. agnus-castus fruits $(0.5 \mathrm{~kg})$ were dried, ground and extracted with $70 \%$ ethanol. The extract was filtered and evaporated under reduced 
pressure. The residue obtained (21.6 gm) was suspended in ethanol: water 1:1 v/v then fractionated using the same solvents as for $A$. annua yielding 11.5, 6.9, 2.8 and $1.4 \mathrm{~g}$, respectively. $\mathrm{The} \mathrm{CH}_{2} \mathrm{Cl}_{2}$ fraction was subjected to silica gel column chromatography to afford 48 fractions, from which, selected subfraction 4 (eluted from $100 \% \mathrm{CH}_{2} \mathrm{Cl}_{2}$ ) was furtherly subjected to normal phase column chromatographic separation with $n$-hexane and ethyl acetate with increasing polarity, then fractionally crystallized to afford compounds (5) and (6). Crystallization of subfractions 13 (eluted from $2 \% \mathrm{MeOH}$ in $\mathrm{CH}_{2} \mathrm{Cl}_{2}$ ) and 33 (eluted from $15 \% \mathrm{MeOH}$ in $\mathrm{CH}_{2} \mathrm{Cl}_{2}$ ) using light petroleum and methanol yielded compounds (7) and (8), respectively.

\section{Reagents, substrates and equipment}

Potassium phosphate buffer, $\mathrm{pH} 7.4$, stored at room temperature. Insect cell expressed baculovirus expressed aromatase + cDNA-expressed NADPH cytochrome $\mathrm{P} 450$ reductase $0.5 \mathrm{nmol} / 0.5 \mathrm{ml}$ or $5 \mathrm{mg} / \mathrm{ml}$ (BD Supersomes ${ }^{\mathrm{TM}}$ enzymes, BD Biosciences), stored at $-80^{\circ} \mathrm{C}$. Fluorometric substrate: Dibenzylfluorescein (Santa Cruz Biotechnology, Headquarters Canada). Prepared as $0.4 \mu \mathrm{M}$, stored at $-20^{\circ} \mathrm{C}$. NADPH regenerating System: solution A, $5 \mathrm{ml}$ (Corning ${ }^{\circledR}$ Gentest $\left.{ }^{\mathrm{TM}}\right)$. This solution contains $20 \mathrm{mg}(26 \mathrm{mM})$ nicotinamide adenine dinucleotide phosphate $(\mathrm{NADP}+)$ and $20 \mathrm{mg}(66 \mathrm{mM})$ glucose-6-phoshate, stored at $-20^{\circ} \mathrm{C}$. NADPH regenerating System, solution $\mathrm{B},\left(\right.$ Corning $^{\circledR}$ Gentest $^{\mathrm{TM}}$ ) containing glucose-6-phosphate dehydrogenase $(\mathrm{G} 6 \mathrm{PDH})$ solution $(40 \mathrm{U})$ in $1 \mathrm{ml}$ of $5 \mathrm{mM}$ sodium citrate, stored at $-20^{\circ} \mathrm{C}$. Assay stop solution: $2 \mathrm{~N}$ sodium hydroxide, Stored at room temperature. Albumin as control protein was prepared at a concentration $0.38 \mathrm{mg} / \mathrm{ml}$. Chrysin standard (Sigma Aldrich Co.) used as positive control for aromatase inhibitory activity.[1]

Aromatase inhibition of the isolated compounds was evaluated by measuring the decrease in fluorescence intensity due to fluorescein, the hydrolysis product of dibenzylfluorescein (DBF), following the procedure previously described by Stresser [11] using a 96 well plate. Briefly, the test sample $(50 \mu \mathrm{l})$ was preincubated with $100 \mu \mathrm{lNADPH}$ regenerating system (containing $1.5 \mathrm{ml}$ cofactor solution A and $0.3 \mathrm{ml}$ of cofactor solution B then completed to $15 \mathrm{ml}$ with $0.5 \mathrm{M}$ potassium phosphate, $\mathrm{pH} 7.4$ buffer) for $30 \mathrm{~min}$ at $37^{\circ} \mathrm{C}$. The final concentration of each compound in the first well was $3.3 \mu \mathrm{M}$, which was used for preparing six further serial dilutions. After then, $100 \mu \mathrm{l}$ of the enzyme and substrate mixture (containing $10 \mu \mathrm{LBF}, 40$ $\mu \mathrm{l}$ of aromatase, and $0.38 \mathrm{mg} / \mathrm{ml}$ albumin completed to $10 \mathrm{ml}$ with $50 \mathrm{mM}$ potassium phosphate, $\mathrm{pH} \mathrm{7.4)} \mathrm{were}$ added to incubate for an additional $30 \mathrm{~min}$ at $37^{\circ} \mathrm{C}$. Finally, the fluorescence of reaction solvent was measured using PerkinElmer HTS 7000 Bio Assay Reader with excitation at $485 \mathrm{~nm}$ and emission at $535 \mathrm{~nm}$. Chrysin was tested as positive control.

$\%$ inhibition was calculated according to the following equation:

$\%$ inhibition $=100-\left[(\right.$ Test inhibitor- positive control $\left.) /(\text { Negative control- positive control })^{*} 100\right]$ [12] $\mathrm{IC}_{50}$ for the tested compounds was determined by fitting the experimental data to a dose-response nonlinear regression curve by using Graphpad Prism (Version 6.01) software.

\section{In-silico studies on the isolated compounds}

\section{Rigid and induced fit docking studies}

The isolated compounds were subjected to rigid and induced fit docking using GLIDE and IFD (Prime module) programs of Schrodinger ${ }^{\circledR}$ suite software.

Ligands were prepared using LigPrep module. They were optimized and energetically minimized through OPLS 3 force field algorithm. Ionization states were predicted at $\mathrm{pH} 7+/-2$ and Epik tool was selected to generate tautomers. Ligands were then desalted and specified chiralities were retained. Structures of unidentified stereochemistry are automatically subjected to all possible conformational changes for selection of best pose. The optimized structures were saved as maestro format (.mae) to retain 3D conformers. The crystal structure of human aromatase (3EQM) was first extracted from PDB and prepared by the aid of protein preparation wizard. The protein was first preprocessed where bond orders and hydrogens are assigned, zero order bonds to metals and disulphide bonds were created. Further, all the water molecules were deleted beyond $5 \AA$ from the active site and iron states in heme at $\mathrm{PH} 7+/-3$ were generated where the one having the lowest state penalty was selected. Once the protein structures were reviewed and modified, Hydrogen bonds were assigned using PROPKA at $\mathrm{PH}=7$ followed by energy minimization using OPLS 3 force field until the relative mean standard deviation (RMSD) of the minimized structure compared to the crystal structure reached $0.30 \AA$. . 
In the IFD protocol included refinement step where ligands were initially docked into the rigid protein using softened-potential Glide docking. The receptor grid was defined as an enclosing box at the centroid of workspace ligand (androstenedione) using an automated-generated box size $(20 \AA)$ with van der Waals radii scaling of 0.5 for both protein and ligands. Protein residues within a distance of $5.0 \AA$ from any ligand poses were kept free to move, and the side chains were restrained, thus taking into account the protein flexibility. A maximum number of 20 poses were retained for each ligand. The protein backbone, side-chains as well as the ligand were energetically minimized using Prime program and the refined 20 ligand pose-complexes were scored by Prime energy. Ligands were re-docked into protein structures within $30 \mathrm{kcal} / \mathrm{mol}$ of the lowest energy structure obtained from the refinement step. The binding energy was computed as Induced fit score (IFD Score) for each ligand pose. The ligand-protein complexes scoring the lowest binding energy expressed by IFD Score, were subjected to deep interaction analyses using Maestro Ligand interaction 2-D and 3D diagrams.[7]

\section{In-silico prediction of pharmacokinetic ADME\&T properties}

The drug-likeness behaviour of the isolated eight compounds from A. annua and $V$. agnus-castus was investigated through the evaluation of their pharmacokinetic (ADME\&T) profiles using QikProp module embedded in Schrodinger ${ }^{\circledR}$ Suite 2017 B software package. [13]

The compounds' structures were compiled from Pubchem database as sdf files. Structures were then imported and prepared by LigPrep module using OPLS3 force field algorithm. Herein, optimization through energy minimization and determination of ionization states at the specified $\mathrm{PH}(7.0+/-3)$ were conducted. Compounds were saved as .mae files then imported to the qikprop wizard for ADME\&T prediction processed in normal mode. Physiochemical and pharmaceutical related descriptors were calculated for each compound where to assess its pharmacokinetic properties. The acceptable range for each descriptor was determined based on the values calculated for $95 \%$ of known drugs.

\section{Results and discussion}

\section{Aromatase inhibitory potential of the major constituents of $A$. annua and $V$. agnus-castus}

Hydro-alcoholic extracts of each plant were fractionated using light petroleum, $\mathrm{CH}_{2} \mathrm{Cl}_{2}$, EtOAc and $n$ $\mathrm{BuOH}$ fractions. Further chromatographic purification of the $\mathrm{CH}_{2} \mathrm{Cl}_{2}$ fractions resulted in the isolation of eight compounds; artemisinin (1) [14], myricetin-3,7,4'-trimethyl ether (2) [15], scopoletin (3) [16] and domesticoside (4) [17] from A. апnиa L. and penduletin-4'-methyl ether (5) [18], casticin (6) [19], $\beta$-sitosterol (7) and $\beta$-sitosterol-3-O- $\beta$-D-glucopyranoside (8) from $V$. agnus-castus L.. The structures of isolated compounds were determined based on studying and analyzing their physical and chemical (Table S1), spectral data (Figures S2 to S7, Tables S2 to S5). as well as reviewing literature Structure elucidation of beta-sitosterol and the glycosidic derivative was estimated by two methods: Co-chromatography using reference standards and solvent systems; Toluene: ethyl acetate $(7: 3 v / v)$ for beta-sitosterol and Methylene chloride: methanol $(9: 1 v / v)$ for the glycosylated derivative. 2D- chromatographic runs were also performed for further identity confirmation. In addition, samples and reference standards solutions were analyzed by HPLC coupled with ELSD detector giving the same retention time values. Of note, myricetin-3,7,4'- trimethyl ether was reported for the first time from genus Artemisia.

The isolated compounds were tested for their aromatase inhibitory activity expressed as $\mathrm{IC}_{50}$ values via constructing dose response curves (Figures S8 and S9). Results in Table 1 revealed that $\beta$-sitosterol was the most active compound possessing the lowest $\mathrm{IC}_{50}$ values of $0.13 \mu \mathrm{M}$. On the contrary, scopoletin was considered the least active compound with an $\mathrm{IC}_{50}$ value of $42.57 \mu \mathrm{M}$. Results also revealed that the isolated tested flavones exhibited lower $\mathrm{IC}_{50}$ values compared to the positive control; chrysin (a known natural aromatase inhibitor) thus, could be considered as relatively potent aromatase inhibitors or drug leads. It was worthy to mention that this is the first report to test these isolated compounds for aromatase inhibition. 
Table 1. Aromatase inhibition of the tested compounds and positive control expressed as $\mathrm{IC}_{50}$ values along with their rigid and flexible XP GScores.

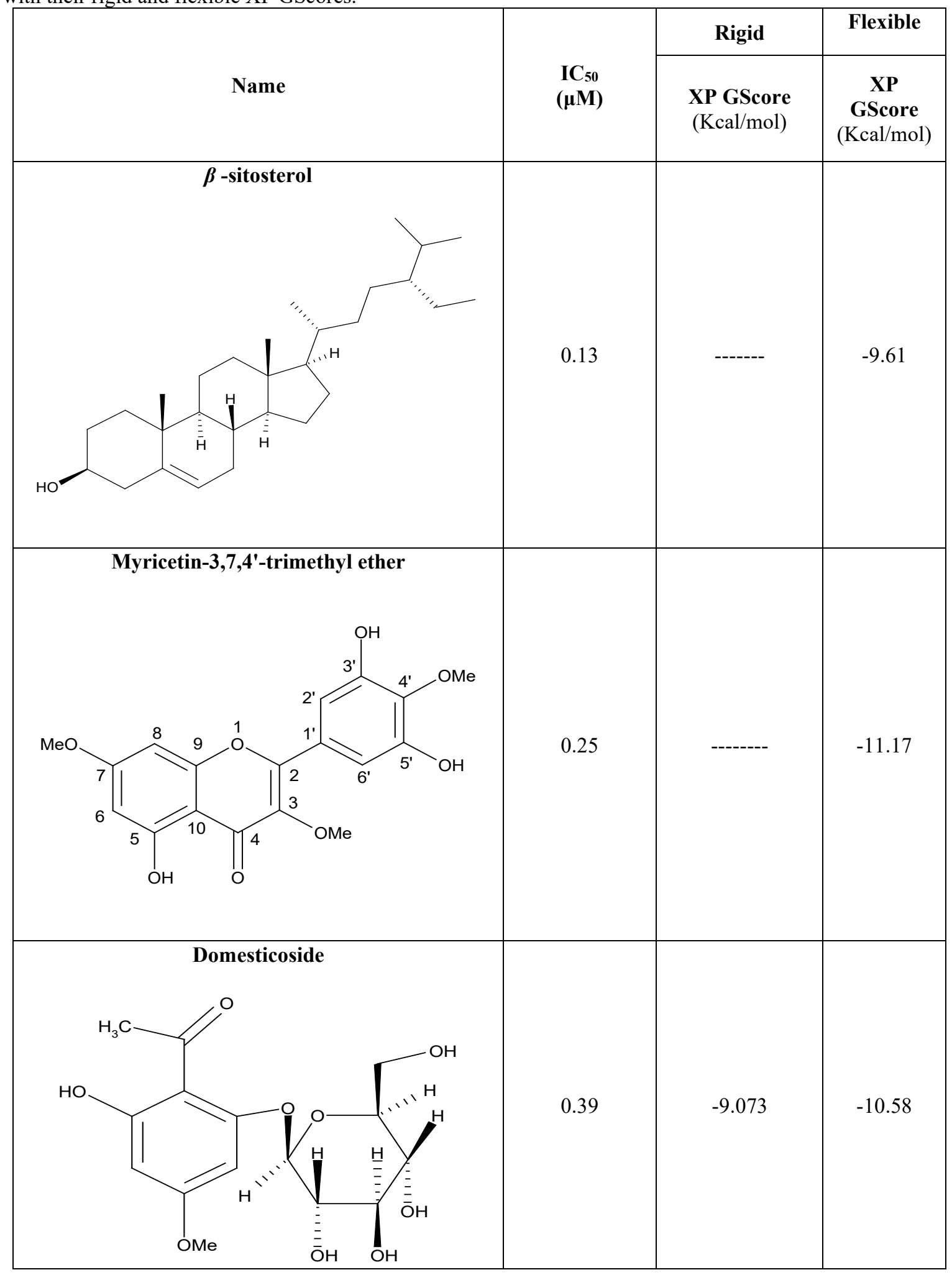




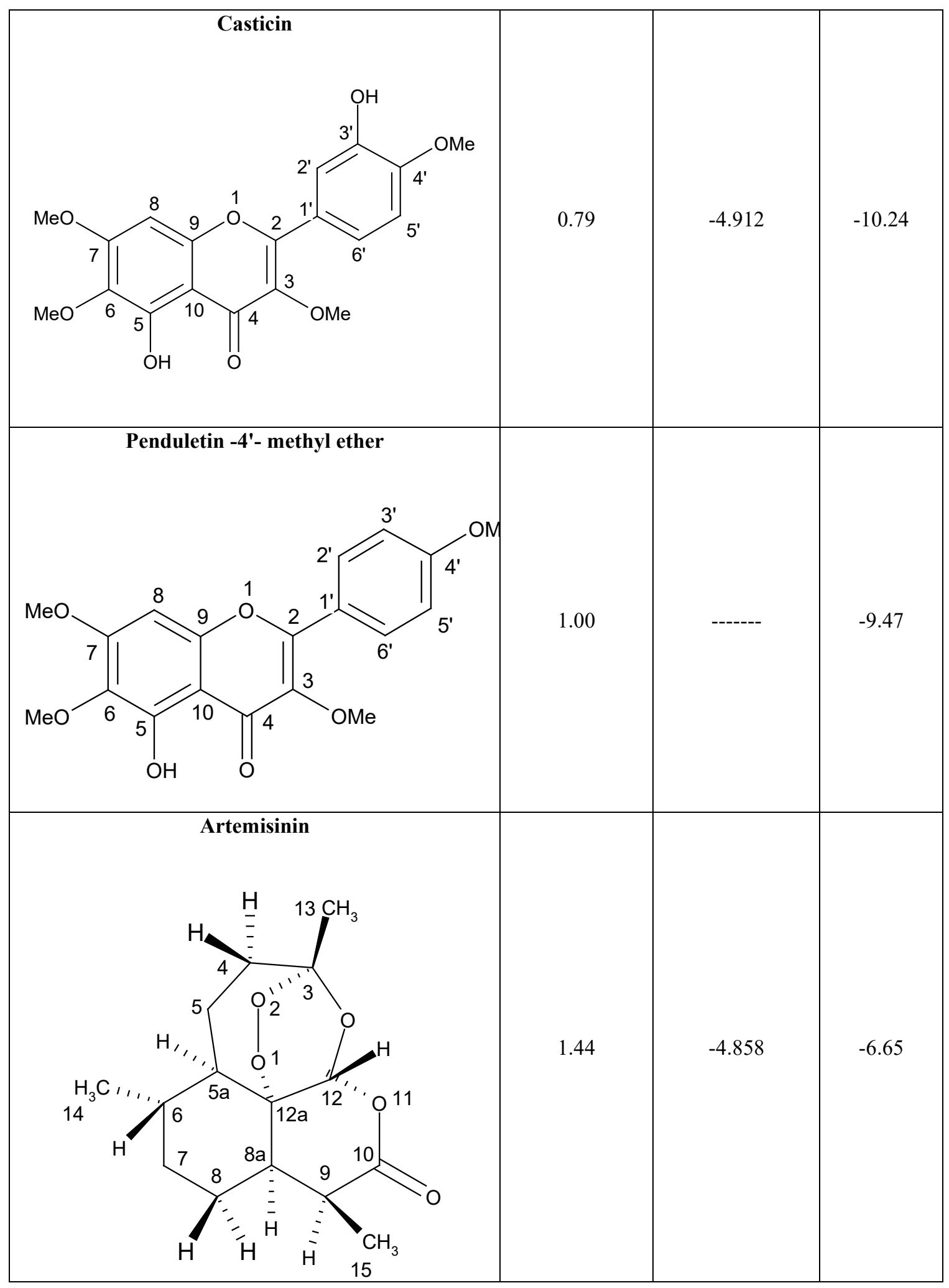




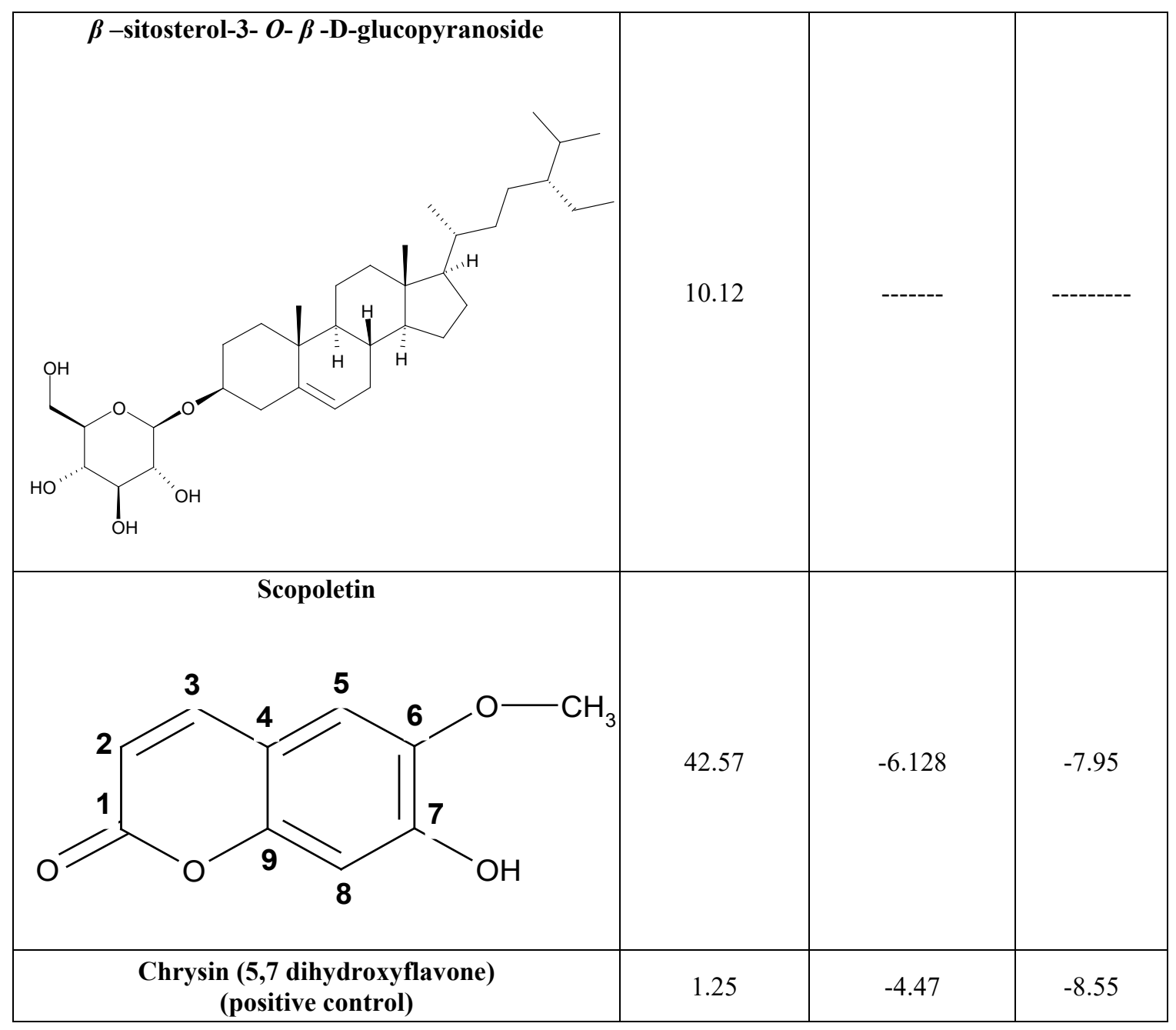

\section{Molecular docking simulation studies}

From Table 1, it was noted that the XP GScores obtained from IFD for artemisinin, scopoletin, domesticoside and casticin were more favorable (more negative) than their corresponding values in rigid docking. It was also interesting to observe that myricetin-3,7,4'-trimethyl ether, penduletin -4'-methyl ether and $\beta$-sitosterol exhibited good GLIDE score values using IFD even though they achieved no scores in rigid docking. This was probably attributed to the considered protein flexibility that allowed for better interactions and higher degrees of binding to the target protein.[20] Interestingly, $\beta$-sitosterol-3- $O-\beta$-D-glucopyranoside showed no XP GScore in docking due to its non-sterically possible poses generated as adopted by GLIDE hierarchical sampling methodology.[21] IFD results were consistent with those obtained from the in-vitro assay where compounds exhibiting more negative docking scores were more likely to be more potent aromatase inhibitors as indicated by their lower $\mathrm{IC}_{50}$ values.

As shown in Fig. 1, the binding mode of the natural substrate androstenedione (co-crystallised ligand) inside the enzyme's active site demonstrated the presence of Hem600 metal, hydrogen bond interactions with Met374 alongside hydrophobic interactions with some backbone residues as Ile133, Phe134, Phe221, Trp224, Ile305, Ala306, Val370, Leu372, Val373, Met374 and Leu477. Additionally, one positive charge interaction with Arg115, another for negative charge interaction with Asp309 and two polar interactions with the amino acid residues Thr310 and Ser478 were also observed. These interactions were in close agreement to those previously reported in literature.[7] 
Insight analysis of the compounds' 2D interaction diagrams (Figures S10 and S11) indicated that their binding sites were in close proximity to those of androstenedione. This reflected that binding was successfully attained in the exact active site or pocket. Comparable interaction patterns to androstenedione could be observed for $\beta$-sitosterol [7] (Fig. 1), however, $\boldsymbol{\beta}$-sitosterol engaged in extra nine hydrophobic interactions with Ile132, Phe148, Met303, Leu152, Pro308, Ala307, Phe203, Leu304 and Met311 beside one extra negative charged interaction with Glu302 and a polar interaction with Ser199. Based on both in-vitro and docking results, $\boldsymbol{\beta}$ sitosterol exhibited the highest aromatase inhibitory activity with an $\mathrm{IC}_{50}$ value of $0.13 \mu \mathrm{M}$ and a GScore of $9.6 \mathrm{kcal} / \mathrm{mol}$. These findings revealed that this compound may serve as a drug lead for designing potent aromatase inhibitors.

The ranking of the flavones from the view of both in-silico (IFD) and in-vitro studies was established as: myricetin-3,7,4'-trimethyl ether $>$ casticin $>$ penduletin -4 '-methyl ether $>$ chrysin. To relate between these data, understanding of the detailed binding modes of these flavones to their target receptor was performed seeking for a clue to their biological activities. Fig.(S10) illustrated the interaction patterns of the isolated flavones compared to both chrysin and vorozole (Fig. S11e) as known potent non-steroidal aromatase inhibitors where more hydrophobic interactions with backbone amino acid residues were observed. Comparative analysis of the isolated flavones' interaction diagrams revealed the presence of two polar interactions with Asp309 and Glu302 in compounds myricetin-3,7,4'-trimethyl ether and casticin compared to only one with Asp309 in penduletin-4'-methyl ether. IFD conformations suggested that myricetin-3,7,4'-trimethyl ether had favorable hydrophobic interactions with some amino acid residues as well as three hydrogen bond interactions with Met374, Leu477 and Asp309, however, casticin possessed similar hydrogen bond interactions with more hydrophobic interactions and an extra metal co-ordination bond with the prosthetic Hem600. This activity order was corroborated by their $\mathrm{IC}_{50}$ values (Table 1 ).

Numerous interactions of domesticoside with aromatase enzyme (Figures S11a and S11b) together with the GScore value $(-10.58 \mathrm{Kcal} / \mathrm{mol})$ verified its high anti-aromatase activity $\left(\mathrm{IC}_{50}=0.39 \mu \mathrm{M}\right)$ in relation with the other compounds. 2D interaction diagrams of the weak inhibitory compounds; artemisinin and scopoletin are also presented in Figures S11c and S11d, respectively.
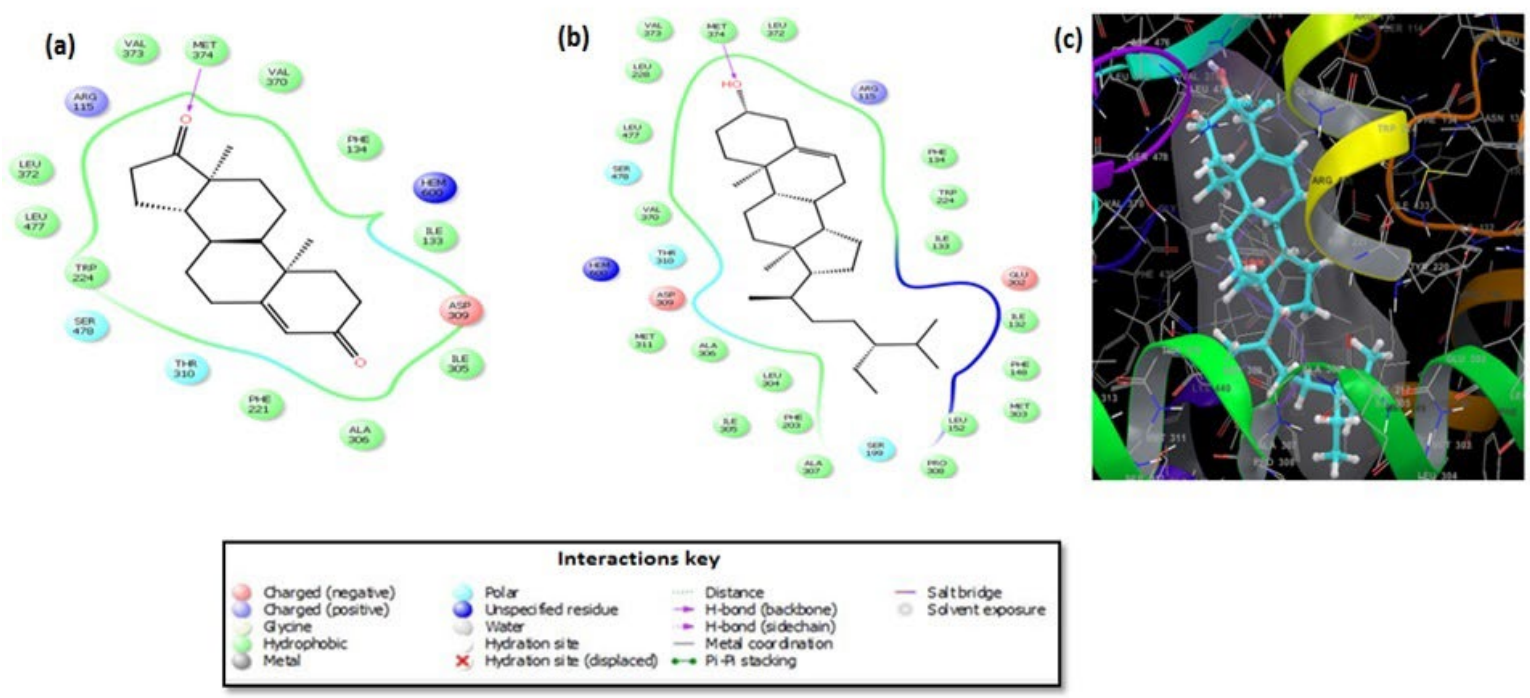

Fig. 1. 2D ligand interaction diagram for docking poses of (a) androstenedione, (b) $\beta$-sitosterol and its (c) 3D interaction diagram in the active site of aromatase crystalline structure (3EQM). 


\section{Pharmacokinetic ADME\&T prediction}

The ADME\&T properties of the active compounds were evaluated using QikProp which predicts some physiochemical properties. From the results tabulated (Table S6), it was observed that all compounds properties lied within the acceptable range for $95 \%$ of known drugs except for $\beta$-sitosterol having 6 stars hence, lying outside the acceptable range.

\section{Prediction of oral absorption}

The oral absorption process of a certain compound depends on many factors such as its solubility, permeability alongside its interactions with metabolizing enzymes and transporters in the gut wall.

QPlog S and CIQP $\log \mathrm{S}$ were computed and used for determination of compounds' solubility. All Compounds except $\beta$-sitosterol and its $\beta$-D- glucoside were found to have acceptable water solubility values suggesting good solubility in the gut, higher contact with its walls and so higher absorption.[22] Sub cut-off values of the above two compounds may be probably attributed to their large molecular weights. Likewise, all compounds showed variable degrees of permeability through the gut wall when calculating their QPPCaco (penetration across gut/blood barrier) values. For instance, $\beta$-sitosterol exhibited great QPPCaco value (3381.617) when compared to that of domesticoside (66.86).

Overall oral absorption of drugs is assessed by the following descriptors: qualitative human oral absorption, \% human oral absorption and Jorgensen's "Rule of Three" (ro3).[23] From all the tested compounds, only $\beta$-sitosterol and its $\beta$-D-glucoside violate one of these rules thus, might have some concerns regarding their oral bioavailability.

\section{Prediction of plasma-protein binding (distribution)}

The drug efficacy is directly related to its binding affinity to plasma proteins (ex: albumin). The more the drug binds to plasma proteins, the less free drug will be available to diffuse to the target organ. In this study, the predicted plasma-protein binding has been estimated by the QPlog KHSA; the prediction of binding to human serum albumin.[24] With the exception of compound $\beta$-sitosterol, all compounds had values that were within the standard range of drug-like compounds. This might be attributed to the hydrophobic nature of the compound which contributed to its strong binding affinity to plasma proteins.[23]

\section{Prediction of first pass metabolism}

QikProp also predicted the number of metabolic reactions the compound is subjected to when orally adminstered. That gave an indication of the accessibility of a compound to the target organ upon reaching the blood stream.[25] The predicted values showed variations within the compounds, from 1 [as in Artemisinin] to 6 [as in myricetin 3,7,4' methyl ether, domesticoside, casticin and $\beta$-sitosterol-3- $O-\beta$-D- glucopyranoside, even though, all values were satisfactory.

\section{Prediction of oral bioavailability}

Oral bioavailability is defined as the part of drug dose that reaches circulation when orally administered. [23] The oral bioavailability of a compound is mainly based on the process of its absorption from gut wall as well as its degree of metabolism in the liver (first pass metabolism). [25] QikProp predicted some physiochemical properties such as molecular weight (mol_MW), solubility (QPlogS and CIQPlogS), number of hydrogen bonds donated to (donorHB) and accepted (accptHB) from water molecules in medium. These four molecular properties constitute the Lipinski rule of 5 which measures the drug-likeness or oral bioavailability of compounds i.e; a compound with a pre-determined biological activity would be considered orally active if it does not score more than 1 in Lipinski's rule. This rule gave indication for the compound pharmacokinetics in living organisms.[8] Results showed that all compounds were great drug like candidates showing acceptable values according to Lipinski rule with the exception of $\beta$-sitosterol- $\beta$-D- glucoside that violate 2 rules raising concerns regarding its bioavailability. Moreover, the optimum values of some descriptors such as polar surface area (PSA) and number of rotatable bonds (\#rotor) had positive impact on the drug oral bioavailability.[26] All compounds' values fell within the recommended range indicating high possibility for finding orally bioavailable candidates within these tested compounds. 


\section{Predicition of excretion profile}

Ideal drugs are characterised by being safe, i.e; rapidly eliminated from the body without causing harm. Excretion process depends on the molecular weight and the partition coefficient $(\log \mathrm{P})$ of the compound thus, small and hydrophilic compounds are more rapidly cleared through kidneys than large, hydrophobic ones.[23] Accordingly, all compounds showed satisfactory $\operatorname{LogP}$ values, except for $\mathrm{QP} \operatorname{logPo} / \mathrm{w}$ and $\mathrm{QP} \log \mathrm{Pw}$ values of compound $\beta$-sitosterol which might be due to its high degree of hydrophobicity.

\section{Prediction of drug related cardiotoxicity}

Clinical studies revealed that potassium channels denoted by HERG $\mathrm{K}^{+}$- that control heart beating and electrical activity - contributed to the cardiotoxicity caused by many therapeutic agents as they block these channels leading to serious arrhythmia. Hence, predicting the $\mathrm{IC}_{50}$ values of $\mathrm{HERG} \mathrm{K}^{+}$blockers using the parameter QPlogHERG might help in evaluating their in-silico cardiotoxicities.[13] Results showed that compounds are devoid of cardiotoxic side effects while, a special warning alarm should be directed to compounds domesticoside, penduletin -4'-methyl ether and $\beta$-sitosterol-3- $O$ - $\beta$-D-glucopyranoside whose values were slightly below the cut off value $(-5)$.

From the above calculated pharmacokinetic parameters, it was concluded that all compounds' properties - except for some of $\beta$-sitosterol - lied within the acceptable range for human use, thereby considered as drug leads for potent aromatase inhibitors.

\section{Conclusion}

From the integrated in-vitro in-silico studies, it can be concluded that $\beta$-sitosterol possessed the most promising aromatase inhibitory activity relative to the other tested compounds, however, some of its pharmacokinetic ADMET properties - especially those depending on solubility - lied outside the acceptable range for human use, therefore, further in-vitro pharmacokinetic experiments are recommended to verify the predicted in-silico results. Also, serious attempts to overcome its poor water solubility probably through modified pharmaceutical formulations should be taken into account. These drug improvements might corporate in presenting $\beta$-sitosterol as a new potent steroidal aromatase inhibitor which has not previously reported for this activity.

Additionally, domesticoside and the flavones; myricetin-3,7,4'-trimethyl ether, casticin, and penduletin-4'-methyl ether exhibited higher potential for aromatase inhibition when compared to the wellreputed aromatase inhibitor chrysin. These findings can qualify them as new promising non-steroidal aromatase inhibitors precursors taking the advantages of their satisfying in-silico pharmacokinetic ADME\&T properities that lied within the acceptable range of the $90 \%$ known drugs. However, intense in-vitro pharmacokinetic studies are recommended to afford better understanding as well as reliable view on their ADME\&T profiles.

\section{Acknowledgments}

This work was financially supported by the Academic Thesis Research Fund (ATRF), faculty of Pharmacy, Alexandria university, Egypt.

\section{References}

1. Jiang, H.; Shi, J.; Li, Y. Molecules 2011, 16, 3146-3151.

2. Balunas, M. J.; Su, B.; Brueggemeier, R. W.; Kinghorn, A. D. Anti-cancer Agents Med. Chem. 2008, $8,646-682$.

3. Balunas, M. J.; Kinghorn, A. D. Planta Med. 2010, 76, 1087. 
4. Ryu, J.-H.; Lee, S.-J.; Kim, M.-J.; Shin, J.-H.; Kang, S.-K.; Cho, K.-M.; Sung, N.-J. J. Korean Soc. Food Sci. Nutr. 2011, 40, 509-516.

5. Al-Zubaidy, A. A. Int. J. Pharm. Sci. Rev. Res. 2014, 29, 303-306.

6. Kaushik, A. C.; Kumar, S.; Wei, D. Q.; Sahi, S. Front. Chem. 2018, 6.

7. Kumavath, R.; Azad, M.; Devarapalli, P.; Tiwari, S.; Kar, S.; Barh, D.; Azevedo, V.; Kumar, A. P. Bioinformation. 2016, 12, 324-331.

8. Tripathi, S. K.; Selvaraj, C.; Singh, S. K.; Reddy, K. K. Med. Chem. Res. 2012, 21, 4239-4251.

9. Hend M. Dawood, R. S. I., Eman Shawky a, Hala M. Hammoda, Aly M. Metwally, Development of a validated HPTLC-bioautographic method for evaluation of aromatase inhibitory activity of plant extracts and their constituents: comparative quantitation using peak area and reciprocal iso-inhibition volume methods.

10. (a) Semenya, S.; Maroyi, A.; Potgieter, M.; Erasmus, L. Afr. J. Tradit., Complementary Altern. Med. 2013, 10, 331-339; (b) Raja, R. R. Afr. J. Plant Sci. 2015, 9, 320-326.

11. Stresser, D. M., High-Throughput Screening of Human Cytochrome P450 Inhibitors Using Fluorometric Substrates: Methodology for 25 Enzyme/Substrate Pairs, Humana Press, 2004, 215-230.

12. Bisswanger, H. Perspect. Sci. 2014, 1, 41-55.

13. Schrödinger, L., QikProp 3.0 User Manual. 2007.

14. Blaskó, G.; Cordell, G. A.; Lankin, D. C. Journal Nat. Prod. 1988, 51, 1273-1276.

15. Yu, S.; Fang, N.; Mabry, T. J. Phytochemistry. 1987, 26, 2131-2133.

16. Brown, G. D.Molecules. 2010, 15, 7603-98.

17. Delnavazi, M.-R.; Hadjiakhoondi, A.; Delazar, A.; Ajani, Y.; Yassa, N., Azerosides A and B: Two new phloroacetophenone glycosides from the roots of Dorema glabrum Fisch. \& C.A. Mey, Vol. 24, 2014.

18. Wollenweber, E.; Schober, I.; Dennis, C. W.; George, Y. Phytochemistry. 1985, 24, 2129-2131.

19. Shaikh, A.; Makhmoor, T.; Choudhary, M., Radical scavenging potential of compounds isolated from Vitex agnus-castus, Vol. 34, 2010, 119.

20. Sarojini, K.; Krishnan, H. Rom. J. Biophy. 2014, 24.

21. Halgren, T. A.; Murphy, R. B.; Friesner, R. A.; Beard, H. S.; Frye, L. L.; Pollard, W. T.; Banks, J. L. J. Med. Chem. 2004, 47, 1750-1759.

22. Pirhadi, S.; Ghasemi, J. B. Mol. Inf. 2012, 31, 856-866.

23. Kalani, K.; Yadav, D. K.; Khan, F.; Srivastava, S. K.; Suri, N. J. Mol. Model. 2012, 18, 3389-3413.

24. Hosen, S. Z.; Dash, R.; Khatun, M.; Akter, R.; Bhuiyan, M. H. R.; Rezaul, M.; Karim, N. J. M.; Ahamed, F.; Islam, K. S.; Afrin, S. J. Appl. Pharm. Sci. 2017, 7, 120-128.

25. Ntie-Kang, F. SpringerPlus. 2013, 2, 353.

26. Khan, M. F.; Verma, G.; Akhtar, W. Arabian J. Chem. 2016. 